\title{
Digestibilidade Aparente da Energia e da Fibra de Dietas para Ovinos Contendo Uréia, Amiréia ou Farelo de Algodão
}

\author{
Jane Maria Bertocco Ezequiel1, Soraia Vanessa Matarazzo르, Ana Karina Dias Salman ${ }^{3}$, \\ Ademir Pereira Martins Júnior ${ }^{2}$, Weber Vilas Bôas Soares ${ }^{3}$, José Renato Caleiro Seixas ${ }^{4}$
}

\begin{abstract}
RESUMO - Este trabalho foi conduzido com o objetivo de avaliar a digestibilidade da energia e da fibra de dietas contendo uréia, amiréia ou farelo de algodão como fontes protéicas exclusivas e silagem de milho como volumoso. Utilizaram-se 24 borregos com 11 meses de idade e peso médio $31 \mathrm{~kg}$ e o método da coleta total de fezes. A ingestão de matéria seca foi de 64,$1 ; 68,8$ e 71,4 g/kg PV0,75/dia e as digestibilidades da energia da FDN e da FB foram 63,0; 67,7 e 64,4\%, 39,6; 55,7 e 50,0\%, 47,0; 49,3 e 53,4\%, respectivamente, para dietas com uréia, amiréia e farelo de algodão. Os ganhos em peso foram 278,5; 348,0; e 293,7 g/anim.dia, na mesma ordem. O uso da amiréia poderá ser o mais adequado, em relação a uréia e farelo de algodão, em dietas para borregos contendo silagem de milho como volumoso.
\end{abstract}

Palavras-chave: amiréia, digestibilidade aparente, energia, farelo de algodão, FDN, uréia

\section{Apparent Digestibility of Energy and Fiber of Sheep Diets Containing Urea, Starea or Cottonseed Meal}

\begin{abstract}
This research was conducted to evaluate the energy and the fiber digestibility of diets containing urea, starea and cottonseed meal as nitrogen sources and corn silage as forage. Twenty-four lambs averaging 11 months old and initial $31 \mathrm{~kg} L W$ and total feces collection method were used. Dry matter intake was $64.1,68.8$ and $71.4 \mathrm{~g} / \mathrm{kg} \mathrm{PV} .75 / \mathrm{day}$ and the energy, NDF and CF digestibilities were $63.0,67.7$ and $64.4 \%, 39.6,55.7$ and $50.0 \%, 47.0,49.3$ and $53.4 \%$, for the diets with urea, starea and cottonseed meal, respectively. The average weights gain were 278.5, 348.0 and $293.7 \mathrm{~g} / \mathrm{anim} . / \mathrm{day}$, in the same above sequence. The use of starea would be more adequate in relation to urea and cottonseed meal in diets with corn silage as forage for lambs.
\end{abstract}

Key Words: apparent digestibility, cottonseed meal, energy, NDF, starea, urea

\section{Introdução}

A fonte protéica utilizada em uma dieta poderá proporcionar diferentes desempenhos aos animais, havendo, assim, o interesse em estudar fontes de proteína verdadeira e de nitrogênio não-protéico (NNP), como a uréia e a amiréia, esta resultante da extrusão da uréia com uma ou mais fontes de amido.

Entre as fontes de NNP, a uréia é a mais comum e de custo mais acessível. Segundo CAMPLING et al. (1960) e RUSSELL et al. ( 1992), esta fonte é prontamente utilizada para a síntese de proteína microbiana no rúmen e atua no crescimento das bactérias digestoras de fibra. Um dos fatores que limita a utilização da uréia é a aceitação pelos animais e sua total solubilidade no ambiente ruminal, o que motivou STILES et al. (1970) e HELMER e BARTLEY (1971) a estudarem processos que minimizassem essas duas características. $\mathrm{O}$ excesso de nitrogênio amoniacal $\left(\mathrm{N}-\mathrm{NH}_{3}\right)$ formado no rúmen poderá, além de acarretar toxicidade, constituir um desperdício energético, ao necessitar energia para eliminar o excesso no sangue. A redução da velocidade de hidrólise em aproximadamente $20 \%$, por intermédio do processo de sua extrusão com o amido de milho, trigo ou mandioca (EZEQUIEL et al., 2000; SILVA, 1999) ou pela adsorção com argilas como a zeolita ( PARRÉ, 1995) tem sido confirmada em recentes pesquisas. Os benefícios desse processamento no desempenho animal tem sido pouco consistentes, entretanto, frente aos recentes avanços na interpretação de degradação ruminal, produção de massa microbianae digestibilidade protéicaintestinal, poder-se-á formular a mistura mais conveniente de alimentos a ser fornecida aos animais, utilizando-se os resultados de aproveitamento da fibra e da energia das dietas.

\footnotetext{
1 Professora do Departamento de Zootecnia - FCAVJ/UNESP - Via de Acesso Prof. Paulo D. Castellane, s/nº. E-mail: janembe@fcav.unesp.br 2 Zootecnista formado pela FCAVJ/UNESP, Jaboticabal, SP.

3 Pós-Graduando da FCAVJ/UNESP.

${ }^{4}$ Zootecnista, Gerente das Rações Fri-Ribe S/A, Pitangueiras. E.mail: joserenato@sp.fri-ribe.com.br
} 
No processo de extrusão, os alimentos ricos em amido, como milho, trigo, arroz, soja e mandioca, são tratados em um sistema composto por uma hélice e uma seção alimentadora, uma para cozimento e outra para dar forma ao alimento. Segundo HARMANN e HARPER (1974), nesse cozimento, ocorre a gelatinização do amido, hidratação das proteínas e mudança da estrutura e viscosidade do grão.

Com base nesses conhecimentos, o objetivo deste trabalho foi avaliar os coeficientes de digestibilidade aparente da energia e da fibra de dietas contendo uréia, amiréia ou farelo de algodão e o ganho em peso de borregos em engorda.

\section{Material e Métodos}

\section{Animais e tratamentos}

Oensaio de digestibilidade foi conduzidoutilizando-se 24 borregos com 11 meses de idade e peso médio de $31 \mathrm{~kg}$, distribuídos em três tratamentos, de acordo com a fonte nitrogenada experimental, uréia, amiréia ou farelo de algodão. As dietas consistiram de silagem de milho como volumoso e milho moído como energético, acrescidos das fontes nitrogenadas e atendiam às exigências do NATIONAL RESEARCH COUNCIL - NRC (1985) para NDT e do AGRICULTURAL RESEARCH COUNCIL - ARC (1980) em energia metabolizável, segundo os valores tabelados de composição de alimentos do NRC (1989). A composição químico-bromatológica dos alimentos utilizados encontra-se na Tabela 1.

A proporção dos ingredientes dos concentrados experimentais e a relação volumoso: concentrado utilizada nas dietas encontram-se na Tabela 2.

Tabela 1 - Composição químico-bromatológica dos alimentos utilizados nas dietas

Tabel 1 - Chemical composition of the feeds used in the diets

\begin{tabular}{lcc}
\hline $\begin{array}{l}\text { Alimento } \\
\text { Feed }\end{array}$ & $\begin{array}{c}\text { MS (\%) } \\
D M\end{array}$ & $\begin{array}{c}\text { PB (\%MS) } \\
C P(\% D M)\end{array}$ \\
\hline $\begin{array}{l}\text { Silagem de milho } \\
\text { Corn silage }\end{array}$ & 32,0 & 9,2 \\
$\begin{array}{l}\text { Milho } \\
\text { Ground corn }\end{array}$ & 89,8 & 10,0 \\
$\begin{array}{l}\text { Farelo de algodão } \\
\text { Cottonseed meal }\end{array}$ & 90,1 & 35,1 \\
$\begin{array}{l}\text { Amiréia } \\
\text { Starea }\end{array}$ & 93,5 & 38,8 \\
Uréia & & \\
Urea & 281,2 & \\
\hline
\end{tabular}

Manejo experimental

Antes de iniciar o período de adaptação, os animais foram pesados em balança com gaiolas para ovinos com sensibilidade para $100 \mathrm{~g}$ e separados em oito blocos conforme o peso. A partir desses dados, os animais foram distribuídos aleatoriamente nos três tratamentos (oito animais/tratamento) e permaneceram em baias coletivas, uma por tratamento, recebendo a dieta experimental específica, até o consumo se estabilizar, o que ocorreu aproximadamente após 14 dias. Os animais foram, então, transferidos para gaiolas individuais de metabolismo providas de comedouro, bebedouro e cocho de sal, onde permaneceram durante sete dias, recebendo as dietas expe-

Tabela 2 - Composição percentual dos concentrados e das dietas e seus teores de proteína, fibra e concentração energética

Tabel 2 - Composition of concentrates and diets and its concentrations of protein, fiber and energy

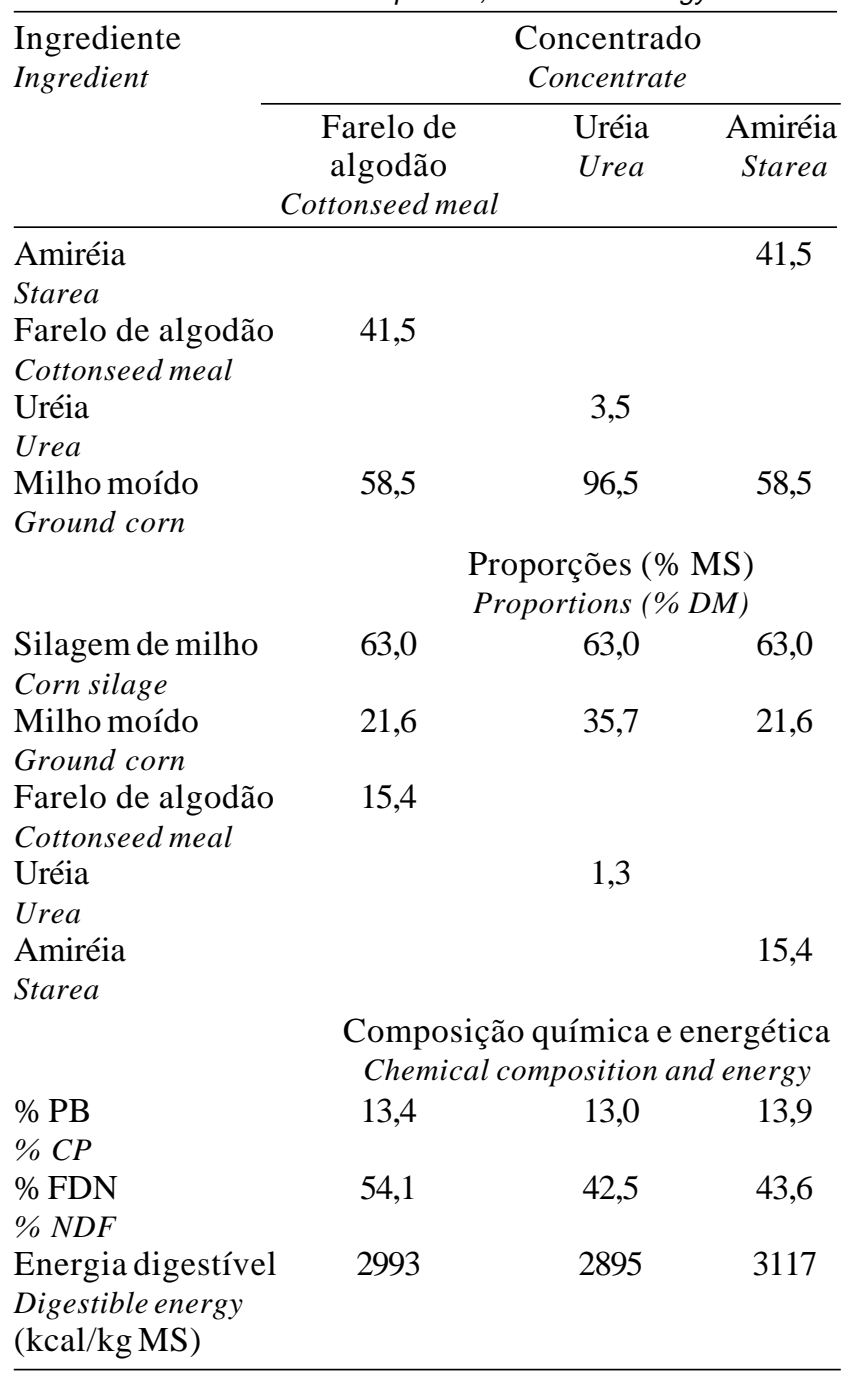


rimentais oferecidas em duas refeições diárias, pela manhã e próximo ao anoitecer. Nos últimos dois dias desse período, os animais foram adaptados com sacolas, para coleta, revestidas com napa. No sétimo dia, realizou-se nova pesagem dos animais para se conhecer o ganho de peso no período.

Nos cinco dias subseqüentes, coletaram-se amostras de alimentos, sobras e fezes. Os alimentos foram fornecidos de maneira que houvesse sobras de aproximadamente $10 \%$ do total ofertado. Apenas no período da manhã coletaram-se as sobras (amostragem de 10\% do total), forneceu-se novo alimento com amostragem de $10 \%$ do total fornecido e coletaram-se as fezes, com amostragem (10\% do total). As amostras de fezes, silagem e sobras foram guardadas de forma composta por animal, em freezer $\left(-20^{\circ} \mathrm{C}\right)$, e as de concentrado, de forma composta por animal, à temperatura ambiente.

Na Tabela 3 encontram-se os resultados de consumo da matéria seca dos tratamentos experimentais.

\section{Análises laboratoriais e estatísticas}

Foram determinadas a matéria seca (MS), (ASSOCIATION OF OFFICIAL AGRICULTURAL CHEMISTS - AOAC, 1995), fibra em detergente neutro-FDN (GOHERING e VAN SOEST, 1970) e energia bruta em bomba calorimétrica (IKA C 400, digital) nas amostras de alimentos fornecidos, nas sobras e fezes.

Os resultados do experimento foram analisados utilizando-se o delineamento em blocos casualizados, com três tratamentos e oito blocos, segundo o modelo matemático $\mathrm{Y}_{\mathrm{ij}}=\mathrm{m}+\mathrm{t}_{\mathrm{i}}+\mathrm{b}_{\mathrm{j}+} \mathrm{e}_{\mathrm{ijk}}$, em que mé média geral; $t_{i}$, o efeito dos tratamentos; $b_{j}$, o efeito dos blocos; $\mathrm{e}_{\mathrm{ijk}}$, o erro aleatório.

Tabela 3 - Ingestão de matéria seca e matéria seca digestível das rações experimentais

Tabel 3 - Dry matter and digestible dry matter intake of the experimental diets

\begin{tabular}{|c|c|c|c|}
\hline & \multicolumn{3}{|c|}{$\begin{array}{c}\text { Ração experimental } \\
\text { Experimental diet }\end{array}$} \\
\hline $\begin{array}{r}\mathrm{F} \\
\text { Cott } \\
\end{array}$ & $\begin{array}{l}\text { arelo de } \\
\text { lgodão } \\
\text { onseed meal }\end{array}$ & $\begin{array}{l}\text { Uréia } \\
\text { Urea }\end{array}$ & $\begin{array}{c}\text { Amiréia } \\
\text { Starea }\end{array}$ \\
\hline $\begin{array}{l}\text { IMS (gMS/UTM/dia })^{1} \\
D M I(g D M / M T U / d a y)\end{array}$ & 71,4 & 64,1 & 68,8 \\
\hline $\begin{array}{l}\operatorname{IMSD}(\mathrm{gMSD} / \mathrm{UTM} / \mathrm{dia})^{1} \\
D D M I(\mathrm{gDM} / M T U / \text { day })\end{array}$ & 55,8 & 40,8 & 57,4 \\
\hline
\end{tabular}

${ }^{1}$ Fonte: SALMAN et al. (1997).

IMS = ingestão de matéria seca ( $D M I=$ drymatter intake); IMSD = ingestão de matéria seca digestível $(D D M I=$ digestible dry matter intake $)$.

\section{Resultados e Discussão}

$\mathrm{Na}$ Tabela 4, encontram-se os resultados de digestibilidade da energia e da FDN. Não se observaram diferenças significativas para os coeficientes de digestibilidade da energia, embora o coeficiente de variação fosse relativamente baixo $(5,95)$ e houvesse variação de $7 \%$ entre a digestibilidade da energia de dietas contendo uréia e aquelas contendo amiréia.

Um fato a ser considerado é que os concentrados das dietas com farelo de algodão continham $54,1 \%$ de FDN, enquanto as dietas com uréia e amiréia, 42,5 e $43,0 \%$ de FDN, respectivamente. RUSSELL et al. (1992) enfatizaram que microrganismos celulolíticos têm grande parte de seu requerimento nitrogenado satisfeito por $\mathrm{N}-\mathrm{NH}_{3}$, o que seria amplamente proporcionado pelas dietas com uréia ou amiréia, que continham 3,5 e 3,2\% de uréia na MS, respectivamente, considerando que a amiréia continha 7,8\% de uréia na MS. Contudo, quando se considerou a FDA das dietas, constatou-se que a dieta contendo uréia apresentou o mais baixo valor de digestibilidade da fibra, mas a presença da amiréia elevou esse valor em 15 unidades percentuais, o que equivaleu a um acréscimo de aproximadamente $40 \%$ dos valores obtidos com a utilização de uréia. Parece, então, que a presença de NNP solúvel não tem o mesmo efeito em dietas completas com abundância de amido, como apresenta o mesmo NNP, quando na forma menos solúvel. CARMO et al. (1999) e EZEQUIEL et al. (2000) estudaram a degradabilidade do nitrogênio do milho extrusado com uréia e verificaram diminuição de cerca de $20 \%$ na solubilidade do nitrogênio, confirmando valores anteriormente obtidos por SILVA (1999).

Outro fator que contribuiria para a ausência de participação da uréia no incremento na digestibilidade da fibra seria o volumoso utilizado, neste caso a silagem de milho, na proporção de $63 \%$ da MS fornecida. Admitindo-se quantidade de grãos na silagem de $35 \%$ da MS, a verdadeira relação volumoso:concentrado seria 41:59, o que poderia estar desfavorecendo o crescimento acentuado de microorganismos celulolíticos no rúmen desses animais. Uma dieta com feno poderia levar a resultados diferentes dos encontrados nesta pesquisa. As concentrações de FDN nas dietas experimentais foram 54,$1 ; 42,5$; e $43,6 \%$ para os tratamentos contendo farelo de algodão, uréia e amiréia, 
EZEQUIEL et al.

Tabela 4 - Coeficientes de digestibilidade da energia e FDN e ganhos médios de peso dos animais Tabel 4 - Digestibility coefficients of energy and NDF and average daily gain of lambs

\begin{tabular}{|c|c|c|c|c|}
\hline \multirow[t]{2}{*}{$\begin{array}{l}\text { Dieta } \\
\text { Diet }\end{array}$} & \multicolumn{3}{|c|}{$\begin{array}{l}\text { Coeficientes de digestibilidade } \\
\text { Coefficients of digestibility }\end{array}$} & \multirow[t]{2}{*}{ CV\% } \\
\hline & $\begin{array}{c}\text { Farelo de algodão } \\
\text { Cottonseed meal }\end{array}$ & $\begin{array}{l}\text { Uréia } \\
\text { Urea }\end{array}$ & $\begin{array}{c}\text { Amiréia } \\
\text { Starea }\end{array}$ & \\
\hline \multirow{6}{*}{$\begin{array}{l}\text { Energia } \\
\text { Energy } \\
\text { FDN } \\
N D F\end{array}$} & $64,4^{\mathrm{a}}$ & $63,0^{\mathrm{a}}$ & $67,7^{\mathrm{a}}$ & 6,0 \\
\hline & & & & \\
\hline & $50,0^{\mathrm{a}}$ & $39,6^{\mathrm{b}}$ & $55,7^{\mathrm{a}}$ & 11,7 \\
\hline & & & & \\
\hline & \multicolumn{4}{|c|}{$\begin{array}{c}\text { Ganhos médio peso diário (g/dia) } \\
\text { Average daily gain }(\mathrm{g} / \text { day })\end{array}$} \\
\hline & $293,7^{\mathrm{a}}$ & $278,5^{a}$ & $348,0^{\mathrm{a}}$ & 52,6 \\
\hline
\end{tabular}

respectivamente. Constatou-se que as dietas contendo uréia ou amiréia apresentaram valores bem próximos de FDN e composição em quantidade e qualidade do concentrado semelhantes (Tabela 1). A maior digestibilidade da FDN obtida foi acompanhada por elevação de $7 \%$ na digestibilidade energética do tratamento com amiréia em relação ao tratamento com uréia.

Constam da Tabela 4 os ganhos em peso obtidos durante o período experimental. As dietas foram balanceadas com previsão de ganho de $250 \mathrm{~g}$ /animal/ dia, o que foi plenamente satisfeito para todos os tratamentos. Entretanto, a dieta com amiréia apresentou valores de ganho em peso 18 e $25 \%$ mais elevados em relação às dietas contendo uréia e farelo de algodão, respectivamente. SEIXAS et al. (1999) obtiveram resultados semelhantes, ao confinarem bovinos, encontrando maior ganho em peso no início do confinamento com dietas à base de amiréia como fonte nitrogenada do que com farelo de algodão. Os resultados aqui obtidos poderiam indicar serem dietas com uréia menos adequadas para situações de estresse, como o que ocorre em gaiolas para estudos digestivos, em relação às dietas com amiréia ou farelo de algodão.

\section{Conclusões}

As digestibilidades da energia e da FB não sofreram influência das fontes nitrogenadas utilizadas, mas a digestibilidade da FDN mostrou-se mais elevada, quando as dietas continham amiréia.

Os ganhos em peso obtidos demonstraram que, em algumas situações de estresse, a utilização de
NNP altamente solúvel pode não ser a melhor alternativa alimentar.

A utilização de amiréia na alimentação de ovinos em engorda mostrou-se satisfatória.

\section{Referências Bibliográficas}

ASSOCIATION OF OFFICIAL AGRICULTURAL CHEMISTS - AOAC. 1995. Official methods of analysis. 16.ed. Washington, D.C. p.1-30.

CAMPLING, R.G., FREER, M., BALCH, C.C. 1960. Factors affecting the voluntary intake by cows. 3 . The effect of urea on voluntary intake of oat straw. Br. J. Nut., 19:1248-1255.

CARMO, F.R.G., EZEQUIEL, J.M.B., GALATI, R.L. et al. Degradabilidade ruminal "in situ" da matéria seca e proteína bruta da amiréia contendo $25 \%$ de uréia com diferentes granulometrias. In: CONGRESSO DE INICIAÇÃO CIENTÍFICA DA UNESP, 11, 1999, Botucatu. Anais... Botucatu, UNESP, 1999. p.254.

AGRICULTURAL RESEARCH COUNCIL - ARC. 1980. The nutrient of ruminant livestock. London: Commonwealth Agricultural Bureaux. 352p.

EZEQUIEL, J.M.B, CARMO, F.R.G., GALATI, R.L. et al. Degradabilidade ruminal in situ da matéria seca e proteína bruta da amiréia nas formas moída e peletizada contendo diferentes níveis de uréia In: REUNIÓNLATINOAMERICANA DE PRODUCCIÓN ANIMAL, 16, CONGRÉSO URUGUAYO DE PRODUCCIÓN ANIMAL, 3, 2000, Mar del Plata. Seción Nutrición (CD-Rom)

GOHERING, H.K., VAN SOEST, P.J. 1970. Forage fiber analyses. Apparatus, reagents, procedures and some applications. Washington: Agricultural Research Service/ United Department of Agriculture. 45p (Agricultural Handbook $n^{\circ} 379$ ).

HARMANN, D.V., HARPER, J.M.1974. Modeling a forming foods extruder. J. Food Sci., 39:1099.

HELMER, L.G.; BARTLEY, E.E. 1971. Progress in the utilization of urea as a protein replacer for ruminants. J. Dairy Sci., 54(1):25-50.

NUTRITIONAL RESEARCH COUNCIL - NRC. 1989. 
Rev. bras. zootec.

Nutrients requeriments of dairy cattle. 6.ed. Washington, D.C.: National Academy of Science. p.89-115.

NUTRITIONAL RESEARCH COUNCIL - NRC.1985. Nutrient requeriment of sheep. 6.ed., Washington, D.C.: National Academy of Science. 99p.

PARRÉ, C. Efeitos da utilização de uréia e zeolita sobre a digestibilidade aparente e o balanço nitrogenado em dietas para ruminantes. Jaboticabal, SP: UNESP. 1995. 96p. Tese (Doutorado em Zootecnia) - Faculdade de Ciências Agrárias e Veterinárias/Universidade Estadual Paulista "Júlio de Mesquita Filho", 1995.

RUSSELL, J.B., O'CONNOR,J.D., FOX, D.G. et al. 1992. A net carbohydrate and protein system for evaluating cattle diets: I. Ruminal fermentation. J. Anim. Sci., 70(11):3551-3561.

SEIXAS, J.R.C., EZEQUIEL, J.M.B., ARAÚJO, W.A et al. 1999. Desempenho de bovinos confinados alimentados com dietas à base de farelo de algodão, uréia ou amiréia. R. Bras. Zootec., 28(2):432-38.
SILVA, L.D.F. Degradabilidade ruminal da casca de soja e fontes protéicas e seus efeitos nas digestibilidades ruminal e intestinal de rações de bovinos. Jaboticabal, SP: UNESP. 1999.110 p. Tese (Doutorado em Zootecnia) - Faculdade de Ciências Agrárias e Veterinárias de Jaboticabal/Universidade Estadual Paulista "Júlio de Mesquita Filho", 1999.

STILES, P.A., BARTLEY, E.E., MEYER, R.M.et al. 1970. Feed processing. VII. Effect of an expansion-processed mixture of grain and urea (Starea) on nitrogen utilization in cattle and on urea toxicity. J. Dairy Sci., 53(10):1436-54.

Recebido em: 30/11/99

Aceito em: 21/09/00 